\title{
PESSOAL
}

35.087 .411 .211

\section{Plano de Pagamento}

\section{Celso de Magalhães}

$A_{\text {retribuição pecuniária percebida pelo empregado particular e pelo }}$ servidor público, como retribuição dos serviços prestados, é fator de suma impcrtância em Administração de Pessoal.

Essa retribuição deve satisfazer a duas condições fundamentais:

— terá de ser justa

- terá de ser suficiente.

Nãc importa que se revista da primeira característica, isto é, pouco se dá que essa remuneração seja justa; se não fôr também suficiente, fugirá à sua finalidade.

Com efeito a retribuição pafa ao homem que trabalha deve garantir-lhe normalmente a estabilidade econômica, defendendo-o contra os embates constantes da vida.

Ainda que considere justo o que recebe, nenhum trabalhador estará adaptado à sua atividade, se o assoberbarem constantes preocupações de vida. Ora, a função do trabalhador é produzir, dar rendimento à emprêsa ou ao Estado; assim, tudo que o desajustar fará baixar-1he a atividade e, conseqüentemente, prejudicará a produção.

E preciso, pois, que a retribuição paga ao trabalhador seja, nãc apenas justa, mas, antes e mais que isso, suficiente.

Para que a retribuição seja justa, basta remunerar-se, pelo seu preciso valor, o trabalho prestado; para que seja suficiente, necessário se torna subordiná-la aos índices do custo de vida e à situação particular de cada trabalhador, pois sòmente assim terá capacidade para custear as necessidades do indivíduo, no lugar onde vive.

Essa é a regra a obedecer.

Não obstante simples no enunciadio, é uma regra de difícil aplicação, pela complexidade de elementos que envolve.

Ao lado dela outra existe, ainda hoje veiculado, coma tendo caráter exclusivc; por repetidores de textos, que se não apercebem da realidade ambiente - "salário igual para trabalho igual".

Não resta dúvida que essa regra apresenta fundamento lógico, e daí a importância que lhe atribuem: o indivíduo deve ganhar pelo que produz. 
Acontece, porém, que a tendência socialista dos Estados Modernos já superou a fase em que a igualdade de tratamento parecia ser o ideal da justiça perfeita.

A justiça social consiste em tratar desigualmente pessoas diferentes.

Poder-se-á alegar que, no Brasil, isso não é verdade, pois a própria Consolidação das Leis do Trabalho dispõe (art. 461) verbis:

"... a todo trabalho de igual valor. . . corresponderá igual salário."

Mas, lcgo adiante, no $\S 1^{\circ}$ do mesmo artigo, verbis:

"Trabalho de igual valor... será o que fôr feito com igual produtividade e com a mesma perfeição técnica, entre pessoas cuja diferença de tempo de serviço não fôr superior a dois anos."

Verifica-se, pois, logo aí, a violação da regra geral - "igual saláric para trabalho igual", na permissão de pagar-se maior salário, ao trabalhador de maior tempo de serviço.

Acresce, porém, que há coisa mais positiva. Com efeito, dispõe a Constituiçãc Federal, no seu art. 157, verbis:

"A legislação do trabalho e a da previdência social obedecerão aos seguintes preceitos, além de outros que visem à melhoria da condição dos trabalhadores:

"I - salário mínimo capaz de satisfazer, conforme as condições de cada regiãc; as necessidades normais do trabalhador e de sua família."

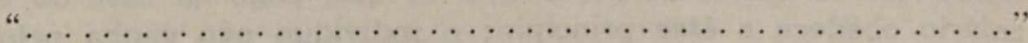

"Diante disso, ninguém poderá contestar que está superada, no Brasil, a regra sediça do - "salário igual para trabalho igual".

Isso não quer dizer, porém, que a fórmula não tenha nenhuma validade nos tempos atuais.

Com efeito, há várias teorias para justificativa do valor do salário pago aos trabalhadores, e ainda hoje de aplicação freqüente:

- o trabalho nada mais é que mercadoria igual às outras; o preço dessa mercadoria é o salário, lçgo, como todo preço, deverá o salário ficar sujeito à grande lei da oferta e da procura. Assim, havendo abundância de trabalhaclor, os salários baixam; havendo escassez, os salários sobem;

- o trabalho é fator da produção, logo, c valor do salário que o remunera dependerá do valor da utilidade que êle produzir;

- o trabalho tem função social, pois o grupo humano é por êle beneficiado; logo, o salário correspondente não pode deixar de levar em conta os encargos sociais do trabalhador.

No estabelecimento de um Plano de Pagamento, há que procurar um ponto de partida e êsse, inegàvelmente, será o estabelecido pela regra - "igual salário para trabalho igual". Daí a ênfase da afirmativa corrente. Todavia, hoje, sòmente isso não bastaria e, pelo contrário, prosseguindo, procura-se estabelecer as diferenças de caráter social, pagando-se mais a quem mais precisa. 
O que leva muita gente, técnicos inclusive, a pensar na predominância do velho princípio é que, na prática, se vale o Estado de artifícios para atender à regra nova, dadas as dificuldades de sua aplicação. É verdade que o saláriofamiliar, criado pela Constituição vigente, ainda não está em vigor, motivando protestos gerais, tôda vez que o Estado fixa novos níveis de salário-mínimo. E que a maioria dos trabalhadores não sabe que o salário-mínimo ainda é de caráter exclusivamente individual, pouco impcrtando que o empregado tenha família ou não, possua muitos ou poucos dependentes.

Mas ainda assim, a existência do salário-família, para os servidores públicos e do abono-familiar, para os empregados particulares, prova que já se aplica nc Brasil, a regra nova de - "a cada um conforme suas necessidades".

Não importa que o dinheiro dado ao indivíduo para atender aos depencientes que possui não provenha da emprêsa onde êle trabalha: o fato é que êle recebe mais, tendo mulher e filhos, que um colega seu, da mesma categoria, mas sem dependentes.

O nível de salário pode ser calculado tomando-se por base:

- o tempo: o trabalhador é retribuído conforme o tempo durante o qual estêve à disposição da emprêsa: mês, dia, hora. Nas atividades privadas, êsses diferentes prazos dão origem aos trabalhadores - mensalistas, diaristas e horistas;

- a produção: o empregado é retribuído conforme a quantidade do produto por êle elaborado. Isso dá origem ao trabalhador tarefeiro.

Os defensores da velha fórmula - "salário igual para trabalho igual" ainda não se aperceberam do fato de que, pago na base do tempo, nenhum salário obedece a êsse princípio: o indivíduo não ganha pelo que faz, mas pelo que poderá fazer. Recebe o mesmo salário tanto quem trabalha produzindo, como aquêle que nada produziu porque nada lhe deram para produzir. E êsse fato não é raro nos serviços públicos, constituindo mesmo a regra predcminante.

Seja baseada no tempo ou na produção, cada forma do pagamento apresenta vantagens e desvantagens.

Assim, se a base fôr o tempo, daí resultará:

- maior segurança econômica para o trabalhador

- afastamento do perigo de estafa

- dificuldade para a emprêsa, na fixação do preço unitáric do produto

- necessidade de maior contrôle do trabalhador.

Com efeito, ganhando na base do tempo, fica o trabalhador certo da importância que terá receber, não precisando, ademais, esforçar-se além do admissível, para aumentar sua féria; por outro lado, terá a emprêsa dificuldade para fixar o preço unitário de cada produto, uma vez que não haverá correlação entre a quantidade produzida e a duração do emprêgo da mão-de-obra, sendo ainda necessário maior contrôle, a fim de que o comcdismo e o desinterêsse do trabalhador não provoquem baixa sensível na produção.

Mas, quando a base do salário fôr a produção, daí resultará:

- maior estímulo para o trabalho 
- perigo de estafa para o trabaihador

- insegurança econômica do empregado

- facilidade na fixação do preço unitário

- perigo de mau acabamento do produto.

Com efeito, percebendo na base da produção, é o trabalhador estimulado a produzir muito; mas isso o poderá levar à estafa, com prejuízos diretos cu indiretos para a emprêsa. Ademais, viverá o trabalhador intranqüilo, por não saber, ao certo, quanto receberá e, na ânsia de receber muito, dará menor atenção à qualidade do produto que elabora, prejudicando, assim, a emprêsa .

Para compensar um e outro sistema, existe o salário-prêmio.

Nêsse tipo de retribuição, paga-se ao trabalhador certo valor fixado para determinada produção normal, ditado pelo critério da teoria salarial adotada, mas se the concede ainde, uma bonificaçãc por qualquer excesso de produção dentro do tempo-base.

Oos salários-prêmio são modalidades atuais da "tarifa-diferencial" de TAYLOR, que ccinsistia no estabelecimento de dois níveis de salário:

- um, máximo, para ser pago a quem, dentro do tempo-base, desse a produção exigida

- outro, mínimo, para ser pago a quem, dentro do mesmo tempo, não atingisse a produção exigida .

Os salários-prêmio cferecem as vantagens da "tarifa-diferencial", sem os inconvenientes dela que, não raro, levavam o trabalhador à estafa.

Há que considerar nos níveis de salário, o valor nominal e o valor real:

- nominal: é o valor do saláric em moeda

- real: é o valor das utilidades que o salário pode comprar.

O salário-nominal é o dinheiro que o empregado recebe; o salário-real é a soma das utilidades que êle pode adquirir com êsse dinheiro. O salário-real e não o nominal é que deverá ser atendido por uma sábia política do Pessoal.

Numa conjuntura econômica normal, confundem-se ambos os salários, o nominal e o real. Assimi, um trabalhador que receba cinca mil cruzeiros mensais poderá adquirir mercadorias e serviços no valor total de cinco mil cruzeiros.

Não raro acontece, porém, que salários e preços se desajustam e aquilo que o empregado recebe já nãc lhe proporciona o equivalente em bens e serviços.

Por exemplo, se o custo da vida aumenta de $20 \%$, quem recebe cinco mil cruzeiros só poderá adquirir mercadorias e serviços, cujo valor total é de quatro mil. Embora continue inalterado seu salário-ncminal, sofreu êle uma redução de mil cruzeiros mensais, sendo, portanto, seu salário-real de quatro mil. 
Dar ênfase ao salário-nominal, como se faz atualmente, descurando do salário-real, é má pcítica econômica e social: tanto prejudica o trabalhador, como ao grupo a que êle pertence.

Na elaboração de Um Plano de Pagamento, há que atender a certos fatốres reputados essenciais, além de outros de caráter secundário, mas não destituídos de importância.

São elementos essenciais:

- classificação de cargc's

- índices do custo de vida

- mercado de trabalho.

São elementos secundários:

- possibilidades financeiras da emprêsa

- repercussões econômicas gerais.

Sem uma adequada classificação de cargos não poderá haver Plano de Pagamento estruturado em bases técnicas. Com efeito, a primeira finalidade do Planc é pagar satisfatòriamente o trabalho produzido. E aqui, exclusivamente aqui, como ponto de particia, domina a velha fórmula — "salário igual para trabalho igual".

Entretanto, o trabalho a ser remunerado não se revela, em regra, por um produto acabado, mas sim pelo conjunto de cibrigações e responsabilidades cometidas ao empregado; ou, doutro modo, o empregada deve ser pago, em geral, pelo que a emprêsa pode exigir dêle e não, realmente, pelo que êle faz. $\mathrm{E}$ aqui se apresenta já modificada a velha fórmula - "igual salário para trabalho igual", por outra - "igual salário para iguais atribuições e responsabilidades".

Ora, ninguém pưderá conhecer, com precisão, qual o grau de habilitação a exigir de um empregado, quais suas responsabilidades, se não souber, exatamente, o que deverá êle fazer.

Se sua função é mais elevada, exige mais preparo e implica em maiores responsabilidades, deve o empregado ganhar mais; logo, sem prévia e correta classificação de cargos, impossível será saber, com justiça, quanto deverá o empregadc ganhar.

E na falta de uma classificação de cargos, todo Plano de Pagamento não passa de uma aventura a agravar ou a gerar injustiças.

Todo servidor federal sabe muito bem disso: basta olhar a situação presente.

O nível do custo de vida, ou os "indices dos preçc's ao consumidor", comc hoje mais tècnicamente se diz, é indispensável na elaboração do Plano de $\mathrm{Pa}$ gamento, pois sòmente êsses índices poderão dizer qual o mínimo necessário para, naquele lugar e naquele tempo, atender às necessidades normais do trabalhador, seja isolado, seja com sua família. E aqui domina então a fórmula moderna de - "a cada um de acôrdo com suas necessidades". 
Nos serviços da União, o princípio é pôstc à margem. Calculando-se uma só tabela de níveis de vencimentos e salários aplicável em todo o país, as remoções dos servidores, para cutras sedes, importam sempre em aumento ou decréscimo na retribuição pecuniária que thes é devida. Com efeito, deslocando-se para um lugar de menor custo de vida, o servidor será beneficiado; deslocando-se para outro de custo de vida maior, será prejudicado. $\mathrm{E}$ isso sem falar na injustiça permanente de pagar o mesmo nível de retribuição a servidores solicitados a encargos sociais e econômicos diferentes, por diferentes serem os lugares onde devem operar.

Mas as ccndições do mercado do trabalho também influem na elaboração do Plano de Pagamento, pelo fato de que sòmente o conhecimento dêsse mercado poderá indicar a retribuição mínima efetivamente paga, o valor da retribuição mais freqüente e o valor máximo pago em determinado lugar.

Com efeito, pouco importa saber que cinco mil cruzeiros bastam para atender às necessidades mínimas do trabalhador, remunerando-o, convenientemente, pelas atribuições e responsabilidades, se o menor salário, naquele lugar, é de seis mil, o mais freqüente de seis mil e quinhentos e o máximo, de sete mil.

Qualquer Plano de Pagamento que só levasse em conta o valor suficiente - cinco mil - estaria prejudicado a emprêsa, por levá-la à impossibilidade de recrutcr ou manter empregados. E aqui domina, então, a teoria do — "salário-mercadoria": havendo escassez, paga-se mais; havendo abundância, pagase menos.

No Brasil, há ainda que atender à legislação específica, pois o saláriomínimo tem caráter legal, isto é, sua fixação pertence ao Gưvêrno. Seu nível depende, exclusivamente, dos índices dos preços ao consumidor, isto é, do custo de vida: alimentação, habitação, vestuário, transporte e higiene.

Embora tal fixação não pcıssa ser reconhecida de valor técnico, o cálculo do salário-mínimo é mais racional que o Plano de Pagamento dos servidores públicos, pcis procura basear-se - e, pelo menos teòricamente o faz - nas necessidades do trabalhador no lugar onde vive.

Assim, ainda que a emprêsa ache êsse mínimo demasiado - e não raro o tem achado - estará na obrigação de pagá-lo, sendo, pois, êsse o ponto de partida para elaboração de seu Plano de Pagamento.

Uma vez atendidcs os elementos essenciais, há que cuidar dos fatôres secundários, dada sua importância na execução do Plano de Pagamento.

Assim, cumpre verificar as possibilidades financeiras da emprêsa. Não basta, em verdade, conhecer o valor justo e suficiente do salário a pagar; é necessário, ainda, saber se o valor té́rico poderá ser pago. Issc tanto se refere às emprêsas particulares, como ao Estado.

Evidentemente, uma emprêsa não pođerá comprometer em salários aquilo que seu rendimento não the permite, pois correrá o risco de falir; da mesma 
forma, o Estado não poderá aventurar-se a operações de crédito ruinosas aos interêsses gerais, para pagar a seus servidores quantias elevadas.

Assim, depois de calculados os valores justos e suficientes, há que adaptálos às pcissibilidades de pagamento, prevalecendo aí a fórmula - "o máximo, dentro do possível".

Existe mais outra questão importante a considerar: são as repercussões econômicas gerais de qualquer Plano de Pagamento. Quando o Estado eleva a retribuição paga a seus servidores, provoca, evidentemente, desequilíbrios na eccnomia das emprêsas, não só porque as poderá privar de elementos bons, naturalmente deslocados para as atividades estatais, de remuneração maior, como ainda por constituir-se fator de estímulo para reivindicações salariais.

Há um exemplo recente: majorados os salários das autarquias federais, os marítimos reclamaram igualdade de tratamento com o pessoal do Lóide Brasileiro Patrimônio Nacional. Não podendo as emprêsasprivadas suportar os ônus de tal equiparação, resolveu o Govêrno subvencioná-las, a fim de evitar perturbações sociais. Não tinha outro recurso.

Mas, não cabe ao Estado suplementar salários das emprêsas: isso é um modo indireto de impor a tôda a coletividade o encargo motivado por uma falta de previsão, ou êrro de técnica.

O Tesourc Público não suporta tais majorações.

E se assim continuar, dentro em pouco todos os trabalhadores serão direta ou indiretamente estipendiados pelo Estado, com tôdas as vantagens da legislação específica, acrescidas àquelas da Consolidação das Leis do Trabalho.

Só vantagens e regalias; nada dəobrigações e responsabilidades .

Mesmo na fixação do salário-minimo é indispensável atender às repercussões econômicas da conjuntura. Muitos males têm sido causados às emprêsas pela postergação, propusitada, dêsse princípio fundamental na política dos salários.

Digo propcsitada, pois os erros clamorosos cometidos não autorizam nutra conclusão, sem grave cfensa à inteligência dcs que os cometem.

Considerando que a base atual dos Planos de Pagamento é eclética, isto e, pagar conforme a produção, consultando o excesso ou escassez da mãu-deobra, mas sem perder de vista a necessidade individual, cumpre estabelecer medidas que tornem o empregado responsável pela baixa da produção provocada por êle mesmo, nos casos de impontualidade horária e falta de assiduidade.

As tolerâncias na abstinência devem ser recuzidas ao mínimo, pois o caráter demagógico que lhe vem sendo dado nos últimos tempos só tem contribuido para onerar a produção, elevando o custo unitário de bens e serviços.

Essa a principal das razões de se terem tornado gravosos muitos produtos nacionais, incapazes de concorrer, atualmente, com similares, no mercado exterior.

Se não é mais possível recuar nas concessões feitas, há, contude; um modo indireto de obrigar à pontualidade e à assiduidade: a progressão salarial, isto 
é, a concessão de aumentos periódicos do salário ao trabalhador que, dentro de determinado período, cumpriu, integralmente, seu horáric de trabalho.

Isso traria ainda a vantagem de permitir a adoção de um sistema de promoções que, realmente, atendesse ao mérito, relegando-se em definitivo a promoção por antiguidade, que não atende ao interêsse do serviço e redunda em fator de desestímulo.

Em resumc; é preciso que a Administração ce Pessoal considere mais o salário-real que o salário-nominal do trabalhador, procurando ajustar-lhe a retribuição pecuniária aos índices de preços. Não deverá, entretanto, descurar de incutir na mentalidade dos que trabalham que a elevação dos preços depende, em grande parte, da elevaşão do custo da mão-de-obra e que, nesse particular, cabe ao trabalhador a maior parcela de responsabilidade.

Ensinar o trabalhador a produzir mais e melhor, para baixar o preço de custo; estimulá-lo a aumentar sua produtividade deve ser matéria de preocupação constante numa boa pcítica de Pessoal, pois constitui fator básico na redução do custo de vida e, pois, no aumenío do salário-real do trabalhador, única forma de aumentar-lhe o padrão-de-vida .

Acabar com o tabu da panacéia do salário-ncminal, é dever precípuo dos que entendem de Plano de Pagamento e cuidam - sem demagogia, realmente - do bem-estar dos que vivem do rendimento do trabalho. 